\title{
Molecular and Genetic Analyses of Two Patients with Pearson's Marrow-Pancreas Syndrome
}

\author{
TADASHI SANO, KYOKO BAN, TAKASHI ICHIKI, MASANORI KOBAYASHI, MASASHI TANAKA, \\ KINJI OHNO, AND TAKAYUKI OZAWA \\ Department of Pediatrics, Nagoya City University Medical School, Nagoya 467 [T.S., K.B., T.I., M.K.] and \\ Department of Biomedical Chemistry, Faculty of Medicine, University of Nagoya, \\ Nagoya 466, Japan [T.S., M.T., K.O., T.O.]
}

\begin{abstract}
Pearson's syndrome, a rare and fatal disorder characterized by refractory sideroblastic anemia and pancreatic insufficiency in infancy, is classified into mitochondrial cytopathies. To understand the molecular and genetic bases of this disorder, we have investigated the mitochondrial respiratory chain enzymes and the mitochondrial DNA (mtDNA) in two Japanese patients with Pearson's syndrome. Immunoblot analysis from various tissues showed the different grades of defects in the subunits of respiratory enzyme complexes. The analyses of mtDNA showed that the deletion in patient 1 spanned 4977 bp from the ATPase 8 gene to the NADH dehydrogenase 5 gene between 13-bp direct repeats, whereas the deletion in patient 2 spanned 3151 bp from the transfer $R_{N A}{ }^{\text {lis }}$ gene to the cytochrome $b$ gene unrelated to any repeated sequences. The deleted mtDNA was heteroplasmic in all the analyzed tissues, but the proportions of deleted mtDNA were quite different. We observed a tendency for the tissue with low percentages of normal-sized mtDNA to show low contents of complex I subunits. Analysis of the entire sequence of both patient's mtDNA showed several nucleotide substitutions including alteration of the initiation codon of the NADH dehydrogenase 5 gene. Some of these nucleotide substitutions might contribute to the phenotypic expression of Pearson's syndrome synergistically with the deletion. (Pediatr Res 34: 105-1 10, 1993)
\end{abstract}

\section{Abbreviations}

mtDNA, mitochondrial DNA

CPEO, chronic progressive external ophthalmoplegia

KSS, Kearns-Sayre syndrome

MELAS, mitochondrial myopathy, encephalopathy, lactic acidosis, and stroke-like episodes

MERRF, myoclonus epilepsy with ragged-red fibers

ND, NADH dehydrogenase

np, nucleotide position

PCR, polymerase chain reaction

rRNA, ribosomal RNA

Pearson's syndrome (McKusick 260560) is a distinctive clinical entity characterized by refractory sideroblastic anemia with vacuolization of marrow precursors, neutropenia, thrombocytopenia, exocrine pancreatic insufficiency, liver failure, and Fanconi's renal tubular acidosis $(1,2)$. Up to now, 20 cases have

Received October 26, 1992; accepted February 10, 1993.

Correspondence and reprint requests: Prof. Takayuki Ozawa, Department of Biomedical Chemistry, Faculty of Medicine, University of Nagoya, 65 Tsurumacho, Showa-ku, Nagoya 466, Japan. been reported (1-7). Rötig et al. (8) reported a large-scale deletion of mtDNA in a patient with Pearson's syndrome. Large-scale deletions of human mtDNA have also been reported in the muscle tissues from patients with CPEO including KSS (9-11). KSS is a multisystem disorder characterized by external ophthalmoplegia, pigmentary retinal degeneration, complete heart block, cerebellar dysfunction, and increase of cerebrospinal fluid protein concentration, but this syndrome generally has neither hematopoietic symptoms nor pancreatic insufficiency. These mitochondrial myopathies and Pearson's syndrome are usually associated with commonly reported deletions of mtDNA, but their clinical manifestations are quite different.

To clarify the molecular and genetic bases of Pearson's syndrome, we analyzed the respiratory enzyme complexes and mutations of mtDNA in various tissues from patients with Pearson's syndrome.

\section{MATERIALS AND METHODS}

Patient 1. This 23-mo-old boy was the second child of healthy and unrelated parents. His 3-y-old sister was healthy. Pregnancy and delivery were uneventful. He was born after 39 wk of gestation with a weight of $3920 \mathrm{~g}$. On the 4th d of life, he was noted to be pale. $\mathrm{Hb}$ concentration was $106 \mathrm{~g} / \mathrm{L}$. One mo later, $\mathrm{Hb}$ concentration became lower than $60 \mathrm{~g} / \mathrm{L}$ and this was accompanied by neutropenia. Throughout his first year, he frequently required blood transfusions. At the age of $23 \mathrm{mo}$, he was admitted to a hospital under the diagnosis of viral enterocolitis. Laboratory examinations at that time showed pancytopenia, elevation of ringed sideroblast $(>15 \%)$ and myeloblast $(11.8 \%)$ in the bone marrow, and lactic acidemia (blood lactate, $754 \mathrm{mg} / \mathrm{L}$; normal value, $<149 \mathrm{mg} / \mathrm{L}$ ). Muscle biopsy showed a preponderance of cytochrome $c$ oxidase-negative fibers. After admission, he became drowsy and later comatose. At the age of $28 \mathrm{mo}$, he died of septicemia with hypoglycemia and severe lactic acidemia.

Patient 2. This 3-mo-old boy was the second child of unrelated parents. His mother and 5-y-old brother were healthy. His father was a carrier of hepatitis B. Pregnancy and delivery were uneventful. He was born after 37 wk of gestation with a weight of $2860 \mathrm{~g}$. He was noted to be pale at birth. On the 1st d of life, he had dyspnea. His blood examinations showed anemia $(\mathrm{Hb}, 82$ $\mathrm{g} / \mathrm{L}$ ) and severe metabolic acidosis ( $\mathrm{pH}, 7.02$; base excess, -27.4). Although his symptoms improved and he was discharged on $\mathrm{d}$ 16 , he was readmitted due to a relapse of severe anemia $(\mathrm{Hb}, 51$ $\mathrm{g} / \mathrm{L}$ ) and lactic acidemia (blood lactate, $686 \mathrm{mg} / \mathrm{L}$ ) at the age of $3 \mathrm{mo}$. From that point up to the present day, a period of $18 \mathrm{mo}$, he has had recurrent episodes of metabolic acidosis and severe anemia requiring transfusions.

Materials. The blood samples for the study were obtained from patient 2 and the family of patient 1 . The other samples, including skeletal muscle, heart, liver, kidney, brain, and pancreas, were taken from autopsied tissues of patient 1 and an age- 
matched control after informed consent of the parents. The interval between death and autopsy was about $1 \mathrm{~h}$ in both cases.

Immunoblot analysis. Mitochondrial proteins from various tissues were separated by electrophoresis in 9.38 to $18.75 \%$ polyacrylamide linear gradient gels (12). The proteins on the gel were transferred to a Durapore filter (Millipore, Bedford, MA) (13) with an addition of $0.1 \%$ SDS. The binding of antibodies to the subunits of the mitochondrial enzyme complexes I, III, IV, and $\mathrm{V}$ on the filter was detected by the peroxidase-antiperoxidase method (14). Antibodies against mitochondrial enzymes were raised in rabbits by intradermal injections of $1 \mathrm{mg}$ of protein for complexes I, III, IV, and V, which were isolated from beef heart mitochondria. Booster injections of the same mixture were administered 3,5 , and $7 \mathrm{wk}$ later. Antisera were obtained $2 \mathrm{wk}$ after the last injection.

The amounts of the immunochemically detectable subunits of complexes were determined by densitometry using a CS-9000 Dual Wavelength Frying Spot Scanner (Shimadzu, Kyoto, Japan). The amounts of the subunits of complexes in each tissue from patient 1 were compared with those in the same tissue from an age-matched control.

Southern blot analysis. To quantify the relative amounts of deleted mtDNA to total mtDNA, $5 \mu \mathrm{g}$ of total DNA extracted from various tissues of patient 1 were digested with 50 units of restriction enzyme PvuII (restriction site: np 2650) or BamHI (restriction site: np 14258) (Takara, Kyoto, Japan) for $8 \mathrm{~h}$, electrophoresed in a $0.8 \%$ agarose gel at $60 \mathrm{~V}$ for $5 \mathrm{~h}$, and transferred to a nylon membrane (Hybond- $\mathrm{N}^{+}$, Amersham, Buckinghamshire, UK) with an addition of $0.4 \mathrm{~N} \mathrm{NaOH}$. A 580bp fragment corresponding to the D-loop region (from $\mathrm{np} 41$ to np 620) of mtDNA was amplified by PCR as described below and was labeled with horseradish peroxidase using an Enhanced Chemiluminescence Hybridization Kit (Amersham). The membrane was hybridized with this probe at $42^{\circ} \mathrm{C}$ for $12 \mathrm{~h}$. Hybridization and washing of the membrane were carried out according to the manufacturer's instructions. Luminol reaction was detected using an $\mathrm{x}$-ray film. The $\mathrm{x}$-ray film was scanned by densitometry (Shimadzu).

Oligonucleotide primers. Primers were synthesized using a model 391 DNA synthesizer (Applied Biosystems, Foster City, CA) and then purified with oligonucleotide purification cartridges from Applied Biosystems according to the manufacturer's instructions. $\mathrm{L}$ and $\mathrm{H}$ primers are 20 -mer oligonucleotides possessing sequences specific for the light (L) strand and the heavy (H) strand of mtDNA.

PCR amplification. Thirty cycles of PCR amplification were performed with $10 \mathrm{ng}$ of total DNA from skeletal muscles and leukocytes, 50 pmol of a pair of $\mathrm{L}$ primer and $\mathrm{H}$ primer, 100 $\mathrm{mM}$ of each deoxyribonucleoside triphosphate, 1.25 units of Taq DNA polymerase (Perkin-Elmer-Cetus, Norwalk, CT) in $10 \mathrm{mM}$ Tris- $\mathrm{HCl}, \mathrm{pH} 8.3,50 \mathrm{mM} \mathrm{KCl}, 1.5 \mathrm{mM} \mathrm{MgCl}$, and $0.01 \%$ gelatin, in a total volume of $50 \mu \mathrm{L}$. This amplification was carried out using a Perkin-Elmer-Cetus thermal cycler with a cycle of denaturation at $94^{\circ} \mathrm{C}$ for $15 \mathrm{~s}$, annealing at $50^{\circ} \mathrm{C}$ for $15 \mathrm{~s}$, and extension at $72^{\circ} \mathrm{C}$ for $80 \mathrm{~s}$. The amplified segments were electrophoresed in a $1.0 \%$ agarose gel in the presence of $0.5 \mu \mathrm{g} / \mathrm{mL}$ ethidium bromide at $100 \mathrm{~V}$ for $30 \mathrm{~min}$.

Primer-shift PCR method. Deleted regions of mtDNA were analyzed by the primer-shift PCR method using several primer pairs (15). When a short fragment corresponding to deleted mtDNA was amplified, a second PCR amplification was performed with nesting primer pairs. If the second PCR amplification did not yield a shorter fragment, either of the primer pair was thought to be present in the deleted segment. If the second PCR amplification yielded a shorter fragment, a third PCR amplification was performed with other nesting primer pairs.

Fluorescence-based direct sequencing. The entire sequence of mtDNA from both patients was determined by the fluorescencebased direct sequencing method (16). Sequencing analysis was performed using a 373A DNA sequencer (Applied Biosystems).
Sequencing reaction was carried out using asymmetrically amplified mtDNA fragments as templates with 10 cycles of denaturation at $90^{\circ} \mathrm{C}$ for $15 \mathrm{~s}$ and annealing and extension at $70^{\circ} \mathrm{C}$ for $1 \mathrm{~min}$. A Taq sequencing kit was obtained from Applied Biosystems. All the nucleotides were compared with the published human mtDNA sequence (17). The entire sequence of mtDNA from 40 subjects including six healthy individuals and 34 patients with various mitochondrial diseases including MELAS, MERRF, KSS, hypertrophic cardiomyopathy, congenital complex I deficiency, Leber's hereditary optic neuropathy, or other myopathies were analyzed as controls.

\section{RESULTS}

Immunoblot analysis. The amounts of the subunits of the mitochondrial respiratory chain complexes I, III, IV, and V from various tissues of patient 1 were analyzed by immunoblotting. This analysis showed severe disproportionate deficiency of complex I subunits. Severe defects were predominantly observed in large molecular weight subunits. This disproportionate deficiency of complex I subunits was basically similar to that observed in tissues from patients with MELAS (14). The relative contents of complex I subunits will be compared with the proportion of deleted DNA present in the later section. The contents of the subunits of complexes III, IV, and V were slightly reduced (Figure 1 shows immunoblotting of complexes I and IV).

Southern blot analysis of $m t D N A$. Southern blot analysis after digestion with $B a m \mathrm{HI}$ revealed two fragments: a 16.6-kb fragment corresponding to normal-sized mtDNA and an 11.6-kb fragment corresponding to deleted mtDNA. The deleted mtDNA was present in all the analyzed tissues, but the proportions of deleted mtDNA were quite different (Fig. 2). Digestion with $P v u I I$ also yielded two other fragments: one was $15.0 \mathrm{~kb}$ instead of $16.6 \mathrm{~kb}$ and the other was $10.0 \mathrm{~kb}$ instead of $11.6 \mathrm{~kb}$. The ratio of the $10.0-\mathrm{kb}$ band to the $15.0-\mathrm{kb}$ band after digestion with PvuII was equal to the ratio of the $11.6-\mathrm{kb}$ band to the $16.6-\mathrm{kb}$ band after digestion with $\mathrm{BamHI}$. A T-to-C transition at np 1005 in the $12 \mathrm{~S}$ rRNA gene observed in patient 1 created a new PvuII site (Fig. 3) and divided a $16.6-\mathrm{kb}$ fragment into a $15.0-\mathrm{kb}$ fragment and a 1.6-kb fragment. This $\mathrm{T}-\mathrm{to}-\mathrm{C}$ transition showed homoplasmy. The $1.6-\mathrm{kb}$ fragment was not detected by the probe used here. The total amounts of mtDNA are not decreased in various tissues as judged by the density of bands in the Southern blot analysis.

Analysis of deleted regions. The size and site of deleted segments in the two patients were analyzed using the primer-shift PCR method. The deleted segment in patient 1 spanned 4977 bp from the ATPase 8 gene to the ND5 gene, whereas the deleted segment in patient 2 spanned $3151 \mathrm{bp}$ from the transfer RNA ${ }^{\mathrm{His}}$ gene to the cytochrome $b$ gene (Fig. 3). Nucleotide sequences at the boundaries of the deleted regions were analyzed using the direct sequencing method. Thirteen-bp direct repeats were detected at the boundaries of the deleted region in patient 1 , whereas neither direct nor indirect repeats were detected at the boundaries of the deleted region in patient 2 .

Comparison between proportions of normal-sized mtDNA and contents of complex I subunits. Figure 4 shows a comparison between the proportions of the normal-sized mtDNA and the contents of complex I subunits among various tissues. The proportions of normal-sized mtDNA to total mtDNA (total mtDNA $=$ normal-sized mtDNA + deleted mtDNA) were distributed in a wide range from $13 \%$ in the liver and pancreas to $57 \%$ in the heart. The contents of complex I subunits in the kidney showed the most obvious deficiency ( $10 \%$ of the control) in proportion to the severe reduction in the percentage of normalsized mtDNA (22\%), whereas the deficiencies of complex I subunits in the heart and the brain were mild (55 and $41 \%$ of the control, respectively) in proportion to the slight reduction in the percentage of normal-sized mtDNA (57 and 33\%, respectively). In the skeletal muscle, the deficiency of complex I sub- 


\begin{tabular}{|c|c|c|c|c|c|}
\hline $\begin{array}{l}\text { Skeletal } \\
\text { muscle }\end{array}$ & Heart & Liver & Kidney & Brain & Pancreas \\
\hline KD & $\therefore \cdots$ & & $\cdots ?$ & 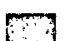 & \\
\hline 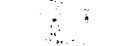 & $\therefore$ & 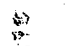 & $\vdots$ & 5 & \\
\hline 75- $\$ 7$ & - & 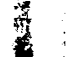 & 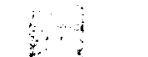 & 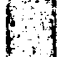 & \\
\hline 52- $=$ & $\exists$ & 繁 & 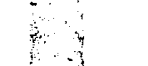 & 5 & \\
\hline $30-$ & $=$ & 3 & $=$ & 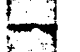 & 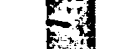 \\
\hline${ }^{24} \hat{\Sigma}$ & $\equiv$ & $=$ & $\equiv$ & & \\
\hline$\because \quad$ & & & : & $\because:$ & \\
\hline$\vdots$ & & & & 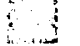 & \\
\hline$C P$ & $C P$ & $c P$ & $C P$ & CP & $c P$ \\
\hline \multicolumn{2}{|c|}{ Complex I } & & C : Control & \multicolumn{2}{|c|}{ P : Patient } \\
\hline $\begin{array}{l}\text { Skeletal } \\
\text { muscle }\end{array}$ & Heart & Liver & Kidney & Brain & Pancreas \\
\hline 5 & $\cdots 4$ & $\because \cdot$ & 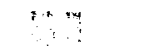 & 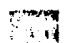 & 73 \\
\hline 4 & $\therefore$ & & $\because$ & 1 & 13 \\
\hline 4 & $\because$ & & 3 & +4 & 13 \\
\hline 8 & 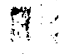 & & 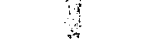 & 1 & 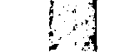 \\
\hline 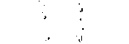 & : & & 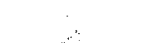 & 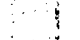 & \\
\hline 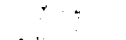 & : & $\therefore$ & $\because$ & 4 & \\
\hline $5==$ & $\overline{=}$ & $\therefore$ & $\cdots$ & $=-$ & -1 \\
\hline & & & $\cdot \cdots:$ & 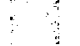 & \\
\hline$c p$ & C P & $c p$ & c p & c P & CP \\
\hline & & & C : Control & P: & ationt \\
\hline
\end{tabular}

Fig. 1. Immunoblot analysis of complexes I and IV of mitochondrial respiratory chain in various tissues of patient 1 . The amounts of subunits of complexes I and IV in each tissue from patient 1 were compared with those in the same tissue from an age-matched control. Immunoblot analysis showed severe disproportionate deficiency of complex I subunits. Severe defects were predominantly observed in large molecular weight subunits. The contents of complex IV subunits were slightly reduced. The amounts of loaded mitochondria protein were $40 \mu \mathrm{g}$ for skeletal muscle, heart muscle, brain, and pancreas, and $80 \mu \mathrm{g}$ for liver and kidney. The numbers 4,5 , and 7 on the left side of the immunoblot for complex IV denote the subunits 4,5 , and 7 of this complex.

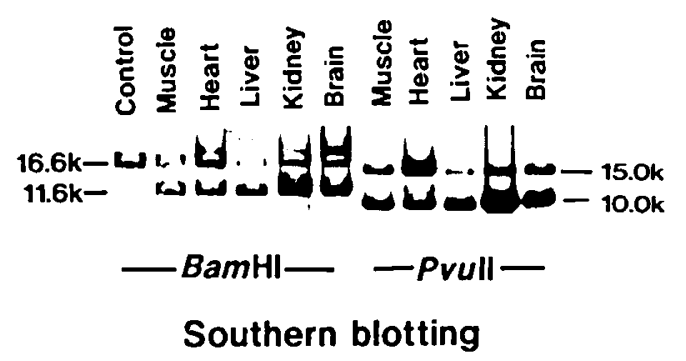

Fig. 2. Southern blot analysis of mtDNA in various tissues of patient 1. Total DNA from various tissues of patient 1 was digested with PvuII or BamHI and hybridized with a probe of 580-bp fragment corresponding to the D-loop region. Southern blot analysis after digestion with Bam HI revealed two fragments in all the analyzed tissues: one was $16.6 \mathrm{~kb}$ (normal-sized mtDNA) and the other was $11.6 \mathrm{~kb}$ (deleted mtDNA). The mtDNA after digestion with $P v u I I$ also revealed two other fragments: one was $15.0 \mathrm{~kb}$ instead of $16.6 \mathrm{~kb}$ and the other was $10.0 \mathrm{~kb}$ instead of $11.6 \mathrm{~kb}$.

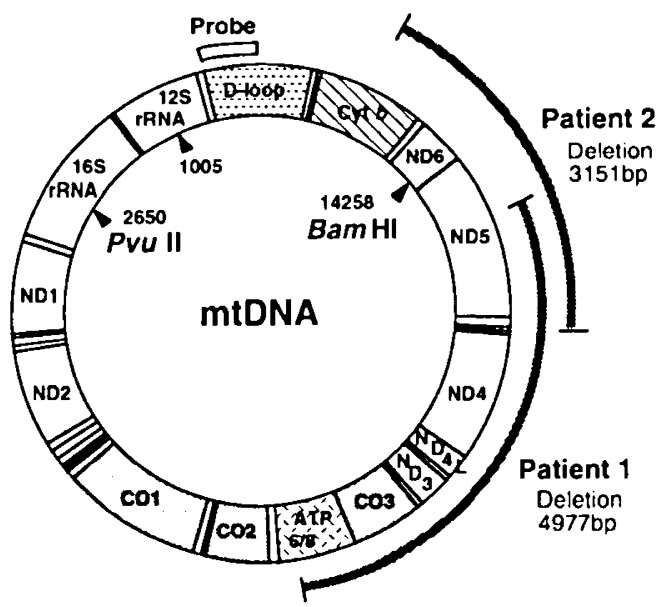

Patient 1

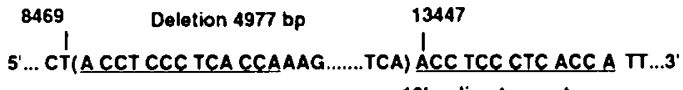

$$
\begin{aligned}
& \text { ATPase } 8 \\
& \text { 13bp direct repeat }
\end{aligned}
$$

$$
\begin{array}{cccc}
\text { Patient } 2 & 12203 & \text { Deletion } 3151 \text { bp } & 15355 \\
\text { IRNA His } & \text { 5... CCCCTTATTT (ACCGAGAA ....... CAC GAA AC) G GGA TCA AAC ...3' } & \text { no direct repeat } & \text { Cyt b }
\end{array}
$$

Fig. 3. The deleted regions and the sequences of the boundaries. The deletion in patient 1 spanned 4977 bp from the ATPase 8 (ATP8) gene to the ND5 gene between 13-bp direct repeats, whereas the deletion in patient 2 spanned 3151 bp from the transfer RNA $^{\text {His }}$ gene to the cytochrome $b(C y t b)$ gene unrelated to any direct repeated sequences.

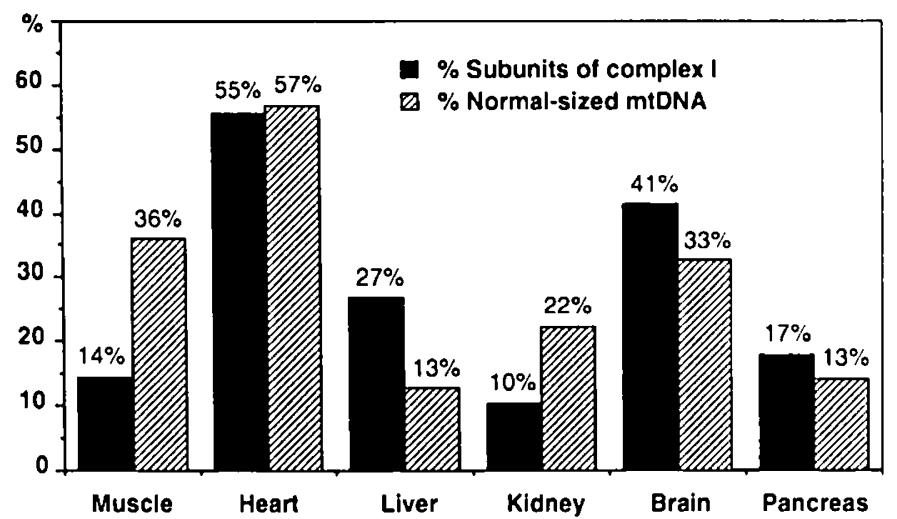

Fig. 4. Comparison between the proportions of normal-sized mtDNA and the contents of complex I subunits in various tissues. The tissues with a high proportion of normal-sized mtDNA contained high amounts of complex I subunits (heart, muscle, and brain), whereas the tissues with a low proportion of normal-sized mtDNA had a severe deficiency of complex I subunits (liver, kidney, and pancreas). In the skeletal muscle, the contents of complex I subunits (14\% of the control) were distinctly less in comparison with the proportion of normal-sized mtDNA (36\%). $\%$ Subunits of complex $I$ represents the ratio of the amounts of complex I subunits in each tissue from patient 1 to those in the same tissue from an age-matched control.

units (14\% of the control) was distinctly severe in comparison with the proportion of normal-sized mtDNA (36\%).

Identification of point mutations in $m t D N A$. The entire sequence of mtDNA from the two patients was directly determined. All the nucleotide substitutions relative to the published human mtDNA sequence (17) were surveyed and compared with the sequences of 40 controls. Table 1 shows a summary of rare (found in less than $10 \%$ of the 40 controls) nucleotide substitutions in the entire mtDNA sequence that were commonly found 
Table 1. Rare* point mutations found in mtDNA of patients with Pearson's syndrome

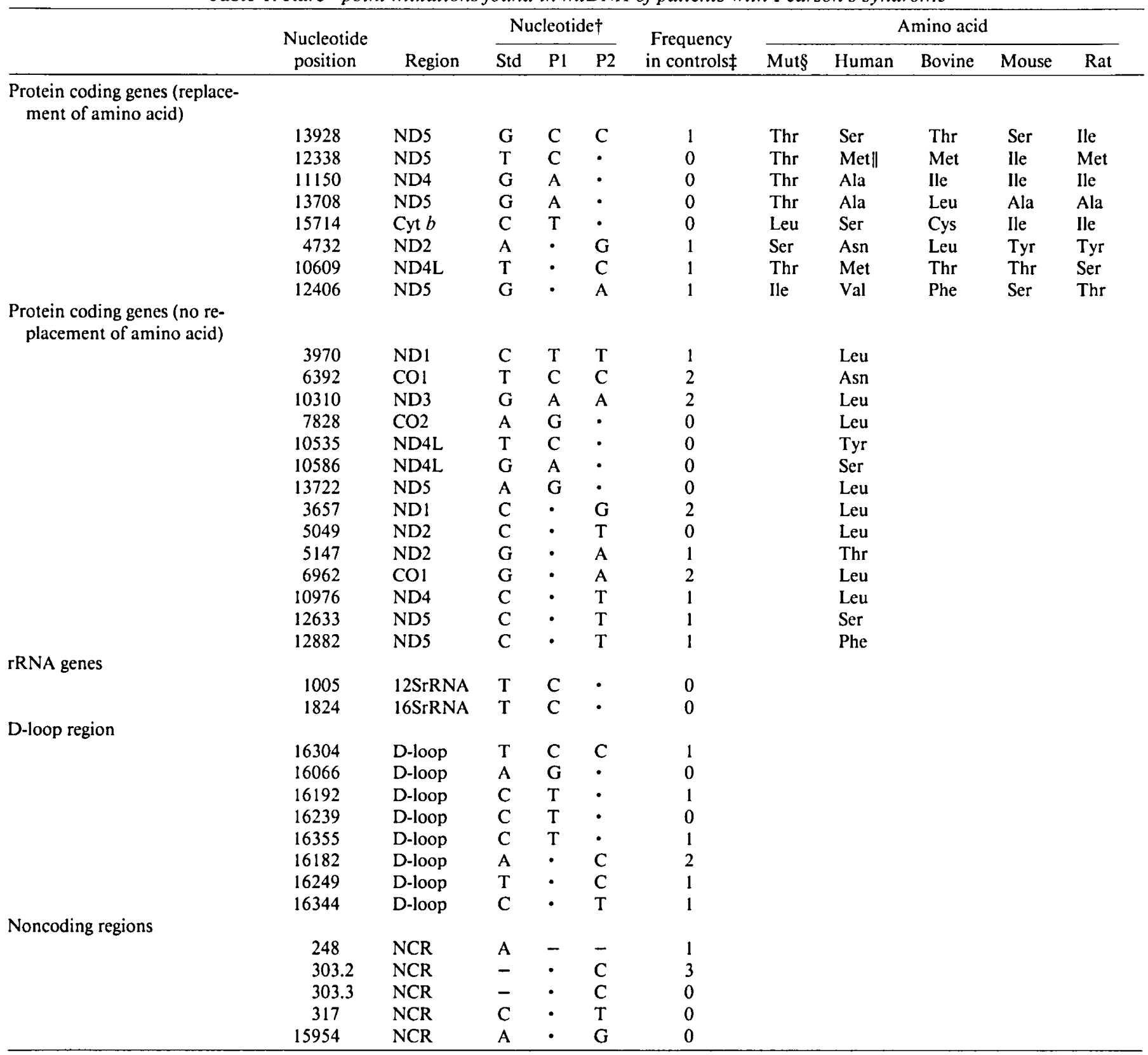

* Rare mutation indicates the mutation found in less than $10 \%$ of controls.

$\dagger$ Std represents the standard mtDNA sequence reported by Anderson $e t$ al. (17); P1 and P2 represent mtDNA sequences found in Patients 1 and 2. Minus sign represents deletion; dot indicates the same as that of the standard nucleotide.

$\ddagger$ Control samples were obtained from 34 patients with MELAS, MERRF, KSS, hypertrophic cardiomyopathy, congenital complex I deficiency, Leber's hereditary optic neuropathy, or other myopathies and six healthy individuals. Number indicates the frequency of subjects with the same mutated mtDNA in 40 controls.

$\S$ Mut represents resulting amino acid substitution.

\| This methionine is the initiation codon of the ND5 gene.

in the two patients. Six common nucleotide substitutions (np $13928,3970,6392,10310,16304$, and 248) were identified in these patients. Although a G-to-C transversion at $\mathrm{np} 13928$ in the ND5 gene causes the replacement from Ser to Thr, Thr at this site can be observed in the bovine gene product. Five other nucleotide substitutions common to these patients were silent, causing no replacements of amino acid. Furthermore, 31 nucleotide substitutions were observed in either patient. A T-to-C transition was found at $\mathrm{np} 12338$ in the ND5 gene in patient 1 but was not found in patient 2 . It is noteworthy that this transition altered the initiation codon ATA for Met in the ND5 gene into ACA, which was normally a codon for Thr. This initiation codon for Met (or Ile) is conserved among four mammalian species. This T-to-C transition was not observed in the 40 controls or in six patients with CPEO. The ACA codon has never been observed in any initiation codons of vertebrate mitochondrial messenger RNA (18). Although six other transitions caused replacements of amino acids, these amino acids were not conserved among four mammalian species. No point mutations in the transfer RNA genes were found in either patient. Two other T-to-C transitions in the rRNA genes (np 1005 in the 12S rRNA gene and $n p 1824$ in the $16 \mathrm{~S}$ rRNA gene) were observed in patient 1 , but not in the 40 controls or in patient 2 . The transition at np 1005 created a new PvuII site. Point mutations 
that potentially induced the occurrence of deletions were not observed in either patient in the regions surrounding the deletions.

Analyses of miDNA in family of patient 1 . We analyzed blood samples from the parents and healthy sister of patient 1 to determine whether the deletion and point mutations identified in patient 1 were transmitted from his parents. Neither Southern blot analysis nor PCR amplification analysis could detect any deletions in the mtDNA from the peripheral blood cells of his parents and sister (data not shown). All the rare nucleotide substitutions identified in patient 1 were also observed in both his mother and sister in a homoplasmic fashion.

\section{DISCUSSION}

We have investigated the mitochondrial respiratory chain enzymes and the mtDNA in two patients with Pearson's syndrome. Although none of our patients had obvious pancreatic insufficiency, they were diagnosed as having Pearson's syndrome on the basis of hematopoietic symptoms and various laboratory findings. The amounts of the subunits of complexes were reduced in all the tissues analyzed in patient 1 (Fig. 1). Complex I showed the severest defect among the respiratory complexes. To clarify the pathogenesis of defects in the respiratory enzyme complexes in Pearson's syndrome, we analyzed the deleted mtDNA in various tissues of patient 1 . The deleted mtDNA was heteroplasmic in all the analyzed tissues, but the proportions of deleted mtDNA were quite different (Fig. 2). Mitochondria have their own DNA coding for 13 subunits of enzyme complexes in the energy-transducing system. Complex I contains the largest number of mtDNA-encoded subunits among the mitochondrial respiratory complexes. The severe defect seems to reflect that complex I is most affected by mtDNA mutations or deletions.

Rötig et al. $(8,19)$ reported a large-scale deletion of mtDNA in a patient with Pearson's syndrome. In recent studies, several mutations of mtDNA associated with neuromuscular disorders have been reported. Deleted mtDNA was identified in patients with CPEO or KSS, whereas several point mutations of mtDNA were reported in patients with MELAS $(16,20,21)$, MERRF $(22,23)$, or Leber's hereditary optic neuropathy $(24,25)$. In the present study, we analyzed both the deletions and the point mutations of mtDNA from two patients with Pearson's syndrome.

The onset of CPEO is usually before adolescence, whereas Pearson's syndrome is characterized by onset in infancy and early death before age $3 \mathrm{y}$. The clinical manifestations of CPEO and Pearson's syndrome are also quite different. The 4977-bp deletion observed in patient 1 (Fig. 3) is identical with the deleted region reported in six of 10 patients with Pearson's syndrome $(6$, $19)$ and in 13 of 30 patients with CPEO (26). Deleted regions in other cases of Pearson's syndrome are quite variable (sizes of deletions: $2.7-7.5 \mathrm{~kb}$; sites of deletions: from the ATPase 8 gene to the cytochrome $b$ gene). It has been reported that there is no correlation between the size or site of the deletion and clinical severity in KSS (27). In the present study, the 3-kb deletion found in patient 2 has never been reported in any other patient with Pearson's syndrome. Although both patients reported here had mtDNA deletions of different location and size, they showed similar clinical symptoms. In patients with CPEO, the deletion of mtDNA is reported to be associated with decreased activity of complex I (26). In the present molecular analysis, we have demonstrated the defects of complex I subunits in the patient with Pearson's syndrome. These observations suggest that CPEO and Pearson's syndrome may have common molecular and genetic mechanisms in pathogenesis. This idea is supported by two reported cases in which patients spontaneously recovered from Pearson's syndrome and later developed CPEO $(5,6)$.

In a case of KSS reported by Hurko et al. (28), the proportion of normal-sized mtDNA was lower in symptomatic postmitotic tissues, namely the brain, heart, and skeletal muscle, than in the liver and kidney. In the present case of Pearson's syndrome, patient 1 , the proportion of normal-sized mtDNA was higher in the asymptomatic postmitotic tissues than in other tissues. We observed a tendency for the tissues with low percentages of normal-sized mtDNA to have low contents of complex I subunits (Fig. 4). However, the liver, which had the lowest proportion of normal-sized mtDNA, and the kidney, which showed the severest defects of complex I subunits, did not manifest severe symptoms. Although a low proportion of normal-sized mtDNA and severe defects of complex I subunits were observed in the pancreas, the exocrine function of the pancreas was normal in this patient. It is also noted that the defect of complex I subunits was distinctly severe in the skeletal muscle in comparison with the proportion of normal-sized mtDNA. These findings suggest that not only the proportion of deleted mtDNA and the degree of defect in the subunits of respiratory complexes but also the energy demands and reserve in each tissue are important in phenotypic expression of the mtDNA mutations.

It is suspected that the small population of deleted mtDNA from the peripheral blood of patients with CPEO is due to slower proliferation of cells with deleted mtDNA (29). Severe anemia in Pearson's syndrome is also explained by dysfunction of hematopoietic cells containing a high population of deleted mtDNA. Spontaneous remission of anemia in some cases of Pearson's syndrome is probably based on preferential selection of hematopoietic cells with a low population of deleted mtDNA. It has been reported that the proportion of deleted mtDNA in the muscle tissue increases with the progress of disease in patients with KSS (5). The gradual deterioration of muscles and the CNS in CPEO may be attributable partly to the gradual increase of deleted mtDNA and partly to the accumulation of deleterious effects of mtDNA deletions in postmitotic tissues. Compared with CPEO, the population of deleted mtDNA in patients with Pearson's syndrome may be much higher in the multiple organs, especially in the hematopoietic tissues, from an early stage of life. One explanation for the severe dysfunction of tissues in Pearson's syndrome is that once the population of deleted mtDNA in the hematopoietic organ and exocrine pancreas accumulates over each critical threshold, the functional impairment of these mitotically active tissues results in severer symptoms and earlier onset.

In the yeast mit $^{-}$mutant, small and discrete mutations are associated with a significant rise in the rate of deletions (30). It is unknown whether some of the nucleotide substitutions found in the present patients increase the instability of mtDNA leading to deletions.

In a case of KSS without anemia, Fischel-Ghodsian et al. (31) recently reported that $75 \%$ of mtDNA from blood cells had a large-scale deletion. This case indicates that tissue distribution of deleted mtDNA may not always be a sufficient explanation for the different phenotypes between Pearson's syndrome and KSS.

We identified several nucleotide substitutions (Table 1) including a T-to-C transition at $\mathrm{np} 12338$ associated with alteration of an initiation codon ATA for Met in the NDS gene into a codon ACA for Thr. Most of the nucleotide substitutions that were commonly observed between two patients seem to be silent mutations. The G-to-C transition at 13928 causes a Ser-to-Thr replacement, but this Ser residue is not conserved among mammalian species. Nucleotide substitutions that were unique to each patient also caused amino acid replacements. The contribution of these nucleotide substitutions, in synergy with the deletion of mtDNA, will provide a possible explanation for distinct phenotypic expressions between KSS and Pearson's syndrome.

Acknowledgments. The authors thank Prof. S. Ohnishi and Dr. T. Imai, Department of Pediatrics, Kagawa Medical School, and Drs. N. Sakura and T. Matsumoto, Department of Pediatrics, Hiroshima University, for providing us with patient tissues; we also thank Prof. Y. Wada, Department of Pediatrics, Nagoya City University Medical School, for advice on our studies. 


\section{REFERENCES}

1. Pearson HA, Lobel JS, Kocoshis SA, Naiman JL, Windmiller J, Lammi AT Hoffman R, Marsh JC 1979 A new syndrome of refractory sideroblastic anemia with vacuolization of marrow precursors and exocrine pancreatic dysfunction. J Pediatr 95:976-984

2. Stoddard RA, McCurnin DC, Shultenover SJ, Wright JE, deLemos RA 1981 Syndrome of refractory sideroblastic anemia with vacuolization of marrow precursors and exocrine pancreatic dysfunction presenting in the neonate. J Pediatr 99:259-261

3. Rötig A, Cormier V, Blanche S, Bonnefont JP, LeDeist F, Romero N, Schmitz J, Rustin P. Fischer A, Saudubray JM, Munnich A 1990 Pearson's marrowpancreas syndrome: a multisystem mitochondrial disorder in infancy. J Clin Invest $86: 1601-1608$

4. Cormier V, Rötig A, Quartino AR, Forni GL, Cerone R, Maier M. Saudubray JM. Munnich A 1990 Widespread multitissue deletions of the mitochondrial genome in the Pearson marrow-pancreas syndrome. J Pediatr 117:599-602

5. Larsson NG, Holme E, Kristiansson B, Oldfors A. Tulinius M 1990 Progressive increase of the mutated mitochondrial DNA fraction in Kearns-Sayre syndrome. Pediatr Res 28:131-136

6. McShane MA, Hammans SR, Sweeney M, Holt IJ, Beattie TJ, Brett EM, Harding AE 1991 Pearson syndrome and mitochondrial encephalomyopathy in a patient with a deletion of mtDNA. Am J Hum Genet 48:39-42

7. Majander A, Suomalainen A, Vettenranta K, Sariola H, Perkkiö M, Holmberg C. Pihko H 1991 Congenital hypoplastic anemia, diabetes, and severe renal tubular dysfunction associated with a mitochondrial DNA deletion. Pediatr Res 30:327-330

8. Rötig A, Colonna M, Blanche S, Fischer A, LeDeist F, Frezal J. Saudubray JM. Munnich A 1988 Deletion of blood mitochondrial DNA in pancytopenia. Lancet 2:567-568

9. Holt IJ, Harding AE, Morgan-Hughes JA 1988 Deletions of muscle mitochondrial DNA in patients with mitochondrial myopathies. Nature 331:717-719

10. Moraes CT, DiMauro S, Zeviani M. Lombes A, Shanske S. Miranda AF, Nakase H. Bonilla E, Werneck LC, Servidei S, Nonaka I, Koga Y. Spiro AJ, Brownell KW, Schmidt B, Schotland DL, Zupanc M. DeVivo DC, Schon EA, Rowland LP 1989 Mitochondrial DNA deletions in progressive external ophthalmoplegia and Kearns-Sayre syndrome. N Engl J Med 320:12931299

11. Ozawa T. Yoneda M, Tanaka M. Ohno K. Sato W, Suzuki H, Nishikimi M, Yamamoto M, Nonaka I, Horai S 1988 Maternal inheritance of deleted mitochondrial DNA in a family with mitochondrial myopathy. Biochem Biophys Res Commun 154:1240-1247

12. Kadenbach B, Jarausch J, Hartmann R, Marle P 1983 Separation of mammalian cytochrome $c$ oxidase into 13 polypeptides by a sodium dodecyl sulfate-gel electrophoretic procedure. Anal Biochem 129:517-521

13. Towbin H, Staehelin T, Gordon J 1979 Electrophoretic transfer of proteins from polyacrylamide gels to nitrocellulose sheets: procedure and some applications. Proc Natl Acad Sci USA 76:4350-4354

14. Ichiki T. Tanaka M, Kobayashi M. Sugiyama N, Suzuki H, Nishikimi M. Ohnishi T. Nonaka I, Wada Y, Ozawa T 1989 Disproportionate deficiency of iron-sulfur clusters and subunits of complex $I$ in mitochondrial encephalomyopathy. Pediatr Res 25:194-201

15. Ota Y, Tanaka M. Sato W, Ohno K. Yamamoto T, Machara M. Negoro T. Watanabe K. Awaya S, Ozawa T 1991 Detection of platelet mitochondrial
DNA deletions in Kearns-Sayre syndrome. Invest Ophthalmol Vis Sci 32:2665-2675

16. Tanaka M, Ino H, Ohno K, Ohbayashi T, Ikebe S, Sano T, Ichiki T, Kobayashi M, Wada Y, Ozawa T 1991 Mitochondrial DNA mutations in mitochondrial myopathy, encephalopathy, lactic acidosis, and stroke-like episodes (MELAS). Biochem Biophys Res Commun 174:861-868

17. Anderson S, Bankier AT, Barrell BG, deBruijn MHL, Coulson AR, Drouin J, Eperon IC, Nierlich DP, Roe BA, Sanger F, Schreier PH, Smith AJH, Staden R, Young IG 1981 Sequence and organization of the human mitochondrial genome. Nature 290:457-465

18. Gadaleta G, Pepe G, DeCandia G, Quagliariello C, Sbisa E, Saccone C 1989 The complete nucleotide sequence of the Rattus norvegicus mitochondrial genome: cryptic signals revealed by comparative analysis between vertebrates. J Mol Evol 28:497-516

19. Rötig A, Cormier V, Koll F, Mize CE, Saudubray JM, Veerman A, Pearson HA, Munnich A 1991 Site-specific deletions of the mitochondrial genome in the Pearson marrow-pancreas syndrome. Genomics 10:502-504

20. Ino $H$, Tanaka M, Ohno K, Hattori K, Ikebe S, Sano T, Ozawa T, Ichiki T, Kobayashi M, Wada Y 1991 Mitochondrial leucine tRNA mutation in a mitochondrial encephalomyopathy. Lancet 337:234-235

21. Goto Y, Nonaka I, Horai S 1990 A mutation in the transfer RNA ${ }^{\text {Leu(UUR) }}$ gene associated with the MELAS subgroup of mitochondrial encephalomyopathies. Nature 348:651-653

22. Shoffner JM, Lott MT, Lezza AMS, Seibel P, Ballinger SW, Wallace DC 1990 Myoclonic epilepsy and ragged-red fiber disease (MERRF) is associated with a mitochondrial DNA tRNA ${ }^{\text {Lys }}$ mutation. Cell 61:931-937

23. Yoneda M, Tanno S, Horai S, Ozawa T, Miyatake T, Tsuji S 1990 A common mitochondrial DNA mutation in the $t-R_{N A}{ }^{\mathrm{L} y z}$ of patients with myoclonus epilepsy associated with ragged-red fibers. Biochem Int 21:789-796

24. Wallace DC, Singh G, Lott MT, Hodge JA, Schurr TG, Lezza AMS, Elsas LJ II, Nikoskelainen EK 1988 Mitochondrial DNA mutation associated with Leber's hereditary optic neuropathy. Science 242:1427-1430

25. Yoneda M, Tsuji S, Yamauchi T, Inuzuka T, Miyatake T, Horai S, Ozawa T 1989 Mitochondrial DNA mutation in family with Leber's hereditary optic neuropathy. Lancet 1:1076-1077

26. Holt IJ, Harding AE, Cooper JM, Schapira AHV, Toscano A, Clark JB, Morgan-Hughes JA 1989 Mitochondrial myopathies: clinical and biochemical features of 30 patients with major deletions of muscle mitochondrial DNA. Ann Neurol 26:699-708

27. Zeviani M, Moraes CT, DiMauro S, Nakase H, Bonilla E, Schon EA, Rowland MD 1988 Deletions of mitochondrial DNA in Kearns-Sayre syndrome. Neurology 38:1339-1346

28. Hurko O, Johns DR, Rutledge SL, Stine OC, Peterson PL, Miller NR, Martens ME, Drachman DB, Brown RH, Lee CP 1990 Heteroplasmy in chronic external ophthalmoplegia: clinical and molecular observations. Pediatr Res 28:542-548

29. Moraes CT, Schon EA, DiMauro S, Miranda AF 1989 Heteroplasmy of mitochondrial genomes in clonal cultures from patients with Kearns-Sayre syndrome. Biochem Biophys Res Commun 160:765-771

30. Linnane AW, Marzuki S, Ozawa T, Tanaka M 1989 Mitochondrial DNA mutations as an important contributor to ageing and degenerative diseases. Lancet 1:642-645

31. Fischel-Ghodsian N, Bohlman C, Prezant TR, Graham Jr JM, Cederbaum SD, Edwards MJ 1992 Deletion in blood mitochondrial DNA in Kearns-Sayre syndrome. Pediatr Res 31:557-560 